\title{
Intraoperative hyperglycemia is independently associated with infectious complications after non-cardiac surgery
}

\author{
Amy M. Shanks ${ }^{1 *} \mathbb{D}$, Derek T. Woodrum ${ }^{1}$, Sathish S. Kumar ${ }^{1}$, Darrell A. Campbell Jr ${ }^{2}$ and Sachin Kheterpal ${ }^{1}$
}

\begin{abstract}
Background: Perioperative hyperglycemia and its associated increase in morbidity and mortality have been well studied in the critical care and cardiac surgery literature. However, there is little data regarding the impact of intraoperative hyperglycemia on post-operative infectious complications in non-cardiac surgery.

Methods: All National Surgery Quality Improvement Program patients undergoing general, vascular, and urological surgery at our tertiary care center were reviewed. After integrating intraoperative glucose measurements from our intraoperative electronic health record, we categorized patients as experiencing mild (8.3-11.0 mmol/L), moderate $(11.1-16.6 \mathrm{mmol} / \mathrm{L})$, and severe $(\geq 16.7 \mathrm{mmol} / \mathrm{L})$ intraoperative hyperglycemia. Using multiple logistic regression to adjust for patient comorbidities and surgical factors, we evaluated the association of hyperglycemia with the primary outcome of postoperative surgical site infection, pneumonia, urinary tract infection, or sepsis within 30 days.
\end{abstract}

Results: Of 13,954 patients reviewed, 3150 patients met inclusion criteria and had an intraoperative glucose measurement. 49\% ( $n=1531)$ of patients experienced hyperglycemia and 15\% ( $n=482)$ patients experienced an infectious complication. Patients with mild (adjusted odds ratio 1.30, 95\% confidence interval [1.01 to 1.68], $p$-value $=0.04$ ) and moderate hyperglycemia (adjusted odds ratio $1.57,95 \%$ confidence interval [1.08-2.28], $p$-value $=0.02)$ had a statistically significant risk-adjusted increase in infectious complications. The model c-statistic was 0.72 [95\% confidence interval 0.69-0.74].

Conclusions: This is one of the first studies to demonstrate an independent relationship between intraoperative hyperglycemia and postoperative infectious complications. Future studies are needed to evaluate a causal relationship and impact of treatment.

Keywords: Hyperglycemia, Infection, Surgery

\section{Background}

Postoperative hyperglycemia has been associated with increased risks of complications among patients undergoing cardiac surgery and critically ill patients [1-5]. In particular, hyperglycemia is thought to decrease the body's immune response and its ability to fight bacterial infection $[1,5,6]$. However, attempts to demonstrate the value of intensive insulin therapy (IIT) have had mixed results, with some studies demonstrating that the risk of

\footnotetext{
*Correspondence: amysha@med.umich.edu

${ }^{1}$ Department of Anesthesiology, Michigan Medicine, 1500 E. Medical Center Dr., SPC 5048, Ann Arbor, Ml 48109, USA

Full list of author information is available at the end of the article
}

hypoglycemia outweighs possible benefits of normoglycemia [6-9]. As a result, even studied populations have had evolving and often contradictory glucose control standards over the last decade.

There is a paucity of intraoperative data regarding patients undergoing non-cardiac surgery with no compelling data guiding the optimal glucose target during or after the operation. Most observational or interventional studies evaluating hyperglycemia and non-cardiac surgery have focused on preoperative or postoperative glucose measurements due to challenges in obtaining intraoperative measurements manually entered into paper or electronic anesthesia records [10-15]. Practicing

(c) The Author(s). 2018 Open Access This article is distributed under the terms of the Creative Commons Attribution 4.0 International License (http://creativecommons.org/licenses/by/4.0/), which permits unrestricted use, distribution, and 
anesthesiologists have no data to guide their intraoperative glycemic management, resulting in wide variation of treatment triggers and definitions of 'tight' control. Two recent randomized controlled trials focused on vascular surgery patients have had conflicting results, with one observing decreased morbidity and mortality associated with tight glucose control, while the other trial failed to observe a statistically significant difference [16-18]. Recently, a prospective study designed to electronically remind clinicians intraoperatively to recheck glucose values on diabetic patients without any specific glucose treatment goals documented a reduced relative risk reduction of $55.4 \%$ in surgical site infections [19]. However, no target glucose ranges for normoglycemia were required and the actual achieved intraoperative glucose values were not reported. A review of the national trial registry databases in both the United Kingdom and United States of America currently found no actively recruiting clinical trials evaluating the relationship between intraoperative glucose thresholds for treating and postoperative infections.

The purpose of the current study was to evaluate the relationship between intraoperative glucose levels and postoperative outcomes in non-cardiac surgery. In particular, evaluating the impact on infectious complications may drive a more specific analysis based upon the pathophysiology of hyperglycemia [13-15]. We hypothesized that patients undergoing major non-cardiac surgery and demonstrating intraoperative hyperglycemia would experience elevated rates of infectious complications. By integrating prospective risk adjustment and 30-day outcome data from the National Surgical Quality Improvement Program (NSQIP) with intraoperative electronic health record (EHR) glucose measurements, a novel database of thousands of patients may inform future studies of hyperglycemia in non-cardiac surgery.

\section{Methods}

Institutional review board approval (University of Michigan, Ann Arbor, Michigan) was obtained for this retrospective observational study at a single academic medical center. As there were no care interventions involved and protected health information were removed after the dataset was created, patient consent was waived as part of the approval.

\section{Patient population}

All adult patients (age $\geq 18$ years) with or without a diagnosis of diabetes mellitus undergoing elective and emergency general, vascular, or urologic procedure were included in this study. Data was extracted from NSQIP data collection process and intraoperative electronic health records at our center from 2005 to 2010.

Patients with a scheduled outpatient procedure were excluded due to low expected infectious complication rate. Additional exclusion criteria were: American Society of Anesthesiologists Physical Status classification (ASA) 5 or 6 , a preoperative systemic inflammatory response syndrome, sepsis, septic shock, pneumonia, preoperative wound classification of dirty, and confirmed pregnancy. Finally, patients without any glucose measurements during the intraoperative period were also excluded.

\section{Data collection}

Data were collected by integrating the local NSQIP database with the departmental perioperative EHR, Centricity $^{\circ}$ (General Electric Healthcare, Waukesha, Wisconsin). The NSQIP methodology has been described previously [20, 21]. For each operation, a trained surgical clinical quality reviewer collects patient demographics, preoperative comorbidities, operative informative, and postoperative adverse occurrences up to 30 days after the operation. Inter-rater reliability data checks are routinely performed and any disagreements $>5 \%$ are investigated. Detailed definitions of NSQIP preoperative patient demographics and comorbidities have been described previously and are available in Additional file 1: Appendix 1 [20, 21].

Intraoperative glucose measurements were obtained from the EHR. This included data from the enterprise laboratory information system and values entered manually by the anesthesiology provider using point of care testing which includes, testing using Accu-Check ${ }^{\circ}$ (Roche Diagnostics, Indianapolis, Indiana), point of care blood gas analysis RapidPoint $400^{\circ}$ (Siemens Medical Solutions, Malvern, Pennsylvania), and formal laboratory testing values. The Accu-Check ${ }^{\bullet}$ point of care device has previously been shown to have an acceptable accuracy over a wide range of hematocrit values in critically ill patients [22]. The EHR data and NSQIP data were linked using patient medical record number combined with anesthesia start date and time using an honest broker system [23]. The use of intraoperative insulin therapy, either intravenous or subcutaneous, as a bolus or infusion, was extracted from the EHR. Once these data were linked, patient identifiers were removed from the analytical dataset. Glucose measurements during the "anesthesia period", defined as anesthesia start to anesthesia end, were included in the analysis. For each period, all of the glucose measurements were retrieved for each patient in order to derive five distinct summary measures: minimum, maximum, median, standard deviation, and glycemic lability index (GLI). The GLI is adapted from the critical care literature and has been demonstrated to be an important measure of glycemic variability [24]. It is calculated as the squared difference between consecutive glucose measures per unit of actual time between those samples and corrected for variant 
number of measurements and observation time. Specifically, the GLI was calculated as:

$$
\begin{aligned}
& \sum\left[\left(\mathrm{Glu}_{\mathrm{n}}-\mathrm{Glu}_{\mathrm{n}+1}\right)^{2} *\left(\mathrm{Time}_{\mathrm{n}+1}-\mathrm{Time}_{\mathrm{n}}\right) \text { in } \text { minutes }^{-1}\right) \\
& \quad *(\text { number of measurements })^{-1} \\
& \left.\quad *(\text { observation time in hours })^{-1}\right]
\end{aligned}
$$

Given the lack of substantial evidence regarding intraoperative hyperglycemia and outcomes in non-cardiac surgery, no existing definitions of elevated glucose levels during surgery were available in the peer-reviewed literature. For the purposes of this analysis, normoglycemia was defined as a maximum glucose of less than $8.3 \mathrm{~mol} / \mathrm{L}$. Using the Delphi Method, mild, moderate, and severe hyperglycemia was defined as a maximum glucose measurement of between 8.3-11.0, between 11.1-16.6, and greater than or equal to $16.7 \mathrm{mmol} / \mathrm{L}$, respectively [25]. These values may underestimate the severity of hyperglycemia compared with general medical literature, but this would bias our results toward the null hypothesis. Moderate and severe hypoglycemia was defined as a minimum glucose measurement of $\leq 3.3$ and $\leq 2.2 \mathrm{mmol} / \mathrm{L}$, respectively. Glucose measurements below $0.5 \mathrm{mmol} / \mathrm{L}$ and above $33.3 \mathrm{mmol} / \mathrm{L}$ were considered data entry errors and not included in these calculations.

\section{Primary outcome}

The primary outcome was the occurrence of one or more of the following infectious morbidity events as defined by NSQIP criteria: surgical site infection (SSI), pneumonia, urinary tract infection, or sepsis. Surgical site infections included superficial SSI, deep incisional SSI, organ space SSI, and wound disruption. The standard NSQIP definitions for each of the complications exclude patients with pre-existing infection of that type. (Additional file 2: Appendix 2).

\section{Statistical analysis}

Statistical analysis was performed using SPSS $^{\circ}$ Version 20 (IBM Inc., Yonkers, New York). Glycemic control was grouped into four categories; normoglycemia, mild hyperglycemia, moderate hyperglycemia, and severe hyperglycemia. Normoglycemia served as the reference group based on the previously stated definitions. In addition, two continuous variables reflecting the glucose standard deviation and GLI were recorded. To adjust for the patient and surgical covariates associated with infectious complications; a multivariable logistic regression model was constructed. Prior to developing the logistic regression model, collinearity diagnostics were performed to ensure that variables were not highly correlated with one another. If the condition index was $>30$, then a bivariate Pearson Correlation matrix would be performed to determine which two covariates were highly correlated $(>0.70)$ [26]. A non-parsimonious logistic regression incorporating covariates and the hyperglycemia groupings, glucose standard deviation and GLI was performed. The covariates used for risk adjustment in this model were: age in years, body mass index $\left(\mathrm{kg} / \mathrm{m}^{2}\right)$, male sex, emergency surgery, prolonged operative duration, dyspnea at rest, dyspnea at exertion, new or worsening congestive heart failure, ASA physical status (as a categorical variable), partially dependent functional status, totally dependent functional status, present of ascites, diabetes mellitus requiring oral hypoglycemic therapy, diabetes mellitus requiring insulin therapy, chronic obstructive pulmonary disease, hypertension, angina, history of cardiac surgery, history of percutaneous coronary intervention, cerebrovascular accident, history of transient ischemic attacks, steroid use for a chronic condition, and preoperative serum albumin. All covariates were based upon NSQIP data and dataset definitions (Additional file 1: Appendix 1) and reflect the covariates with the greatest contribution to the NSQIP risk adjustment model [27]. In cases where serum albumin was not available, it was imputed as the median of the patient population. In addition, the underlying risk of each surgical procedure was incorporated using a surgical risk score derived based upon previously described and validated methodology for NSQIP analyses [28]. The derivation dataset for this surgical risk score was the national 2005-2010 NSQIP participant use data file. The surgical risk score is a continuous variable that reflects the underlying risk of the procedure performed, based upon primary common procedural terminology (CPT) codes. The CPT code was developed by the American Medical Association as a way to unify surgical procedures. The codes are broken down into three categories. The highest category is the body region that is being operated on and then can be sub-divided into specific areas within the region or more complex versus less complex surgical techniques. A lower score would indicate the surgical procedure has less risk of post-operative infection and a higher score would indicate the patient is at a greater risk for post-operative infection. Prolonged operative duration is a binary variable based upon the Center for Disease Control's existing methodology for SSI risk adjustment. It is defined as an operative duration above the 75th percentile for the primary CPT code using national benchmark data. The national benchmark dataset used for this analysis was the 2005-2010 national NSQIP participant use data file. All glucose exposure variables were also included in this model. The goodness of fit of the model was assessed using the Omnibus Tests of Model Coefficients and the Hosmer and Lemeshow Test. All covariates deemed to be significant in the model ( $p$-value $\leq 0.05)$ 
were established as independent predictors of an infectious complication. Measures of effect size were reported using the adjusted odds ratio calculated by the logistic regression full model fit [29]. The resulting model's predictive value was evaluated using the c-statistic for dichotomous outcome [30].

\section{Sensitivity analysis}

A pre-specified sensitivity analysis was performed for all non-diabetic patients using the same non-parsimonious logistic regression techniques and assessment for goodness of fit and the model's predictive value. Due to the small sample size for diabetic patients, it was not possible to perform a sensitivity analysis due to the model becoming grossly over-fitted.

Two societies have recommended guidelines to target intraoperative glucose under $10 \mathrm{mmol} / \mathrm{L}$ for diabetic ambulatory surgical patients and for adult cardiac surgical patients [31, 32]. Therefore, a sensitivity analysis was performed using the same non-parsimonious logistic regression techniques but replacing the previously stated four hyperglycemia groups with a hyperglycemia definition of intraoperative glucose $\geq 10 \mathrm{mmol} / \mathrm{L}$.

Additionally, intraoperative blood transfusions have been shown to be associated with an increase in complications post-operatively [33]. We performed a sensitivity analysis to incorporate the number of units of red blood cells (RBC) administered intraoperatively to our study cohort to investigate if hyperglycemia and RBC are associated with increased risk of postoperative infectious complications.

\section{Power analysis}

Preliminary data (approximately 14,000 patients) allowed us to ascertain that approximately $30 \%$ would include a perioperative glucose measurement and $10 \%$ would experience the primary outcome [34]. As a result, we assumed that approximately 300 patients would experience the primary outcome and provide adequate power for a multivariable logistic regression model.

\section{Results}

13,954 patients with integrated NSQIP and intraoperative EHR were identified. After planned exclusion criteria, 8501 patients undergoing major non-cardiac surgery were identified. Of these, 5351 did not have a perioperative glucose measurement in EHR, resulting in a final analysis dataset of 3150 patients (Fig. 1). A comprehensive listing of procedures included and sample sizes is available in Additional file 3: Appendix 3.

The mean number of measurements per patient was three. 1619 (51\%) patients were normoglycemic, 1042 (33\%) patients experienced mild hyperglycemia, 442 (14\%) experienced moderate hyperglycemia, and 47

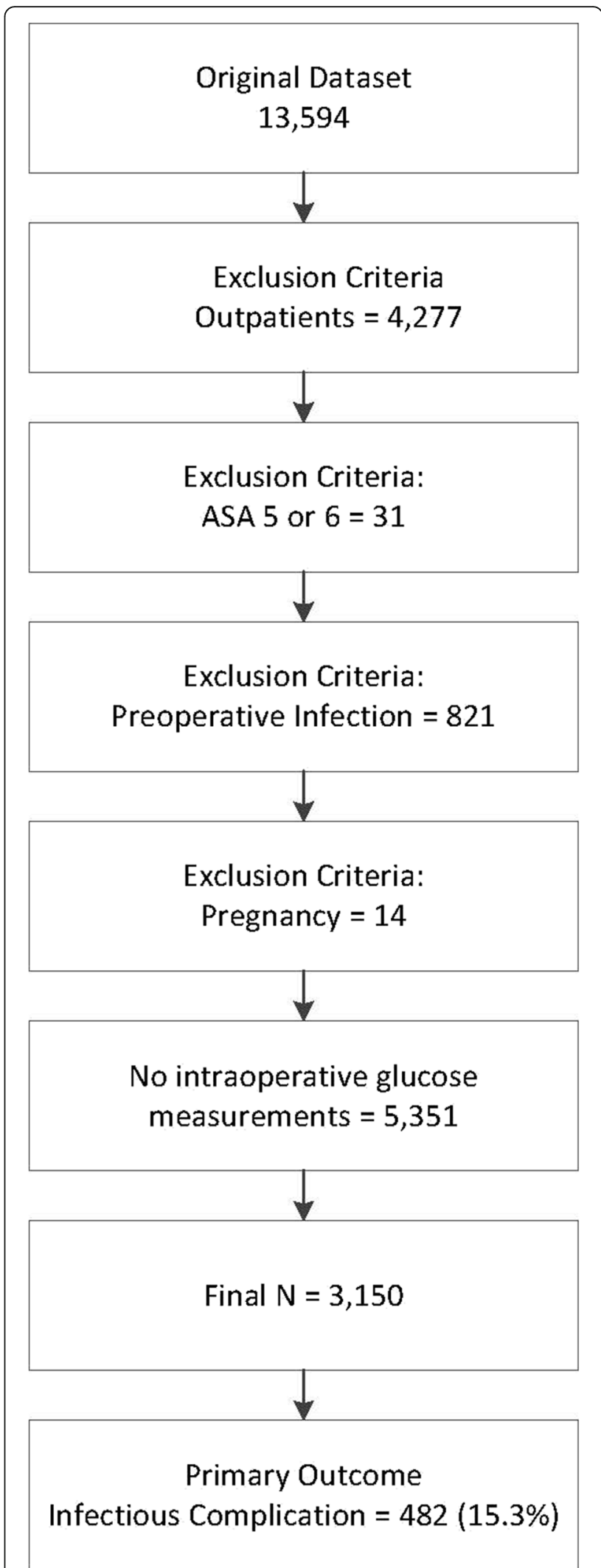

Fig. 1 Study selection criteria. Abbreviations: ASA = American Society of Anesthesiologists Physical Status classification 
(1.5\%) experienced severe hyperglycemia. Only 33 patients (1.0\%) experienced moderate hypoglycemia while 17 (0.5\%) patients experienced severe hypoglycemia (Table 1). Patients experiencing increasing severity of hyperglycemia in general had more comorbidities (Table 2). Overall, $45 \%$ of patients demonstrating hyperglycemia did receive intraoperative insulin therapy (32\% of mild, $70 \%$ of moderate, and $83 \%$ of severe hyperglycemia patients). Diabetic patients compared with their non-diabetic counterparts were more likely to demonstrate all levels of hyperglycemia, but not hypoglycemia (Table 1). Overall, 482 (15\%) patients experienced a composite postoperative infectious complication (Table 3). The maximum intraoperative glucose distribution for patients with and without the composite postoperative infectious complication as well as the individual infectious complications are shown in Additional file 4: Appendix 4.

Covariate adjusted logistic regression analysis included 3036 patients $(96 \%)$ with complete data. Compared with normoglycemic controls, patients with mild hyperglycemia had a statistically significant risk-adjusted increase in infectious complications (adjusted odds ratio (AOR)1.30 [95\% confidence interval (CI) 1.01 to 1.68], $p$-value $=0.04)$. Compared with normoglycemic controls, patients with moderate hyperglycemia also had a statistically significant risk-adjusted increase in infections complications (AOR 1.57 [95\% CI 1.09-2.28], $p$-value = 0.02) (Fig. 2). Severe hyperglycemia, glucose standard deviation, and GLI did not demonstrate a statistically significant independent relationship. Additional covariates with an independent association to the primary infectious outcome were: male sex (protective), dyspnea at moderate exertion, functional status (both partially and totally dependent), preoperative serum albumin level, chronic obstructive pulmonary disease, prolonged operative duration, and surgical risk score. The model's c-statistic was 0.72 [95\% CI 0.69-0.74] and the omnibus test of model coefficients resulting in a chi-square of 242.0, 29 degrees of freedom, and $p$-value $<0.001$. The

Table 1 Prevalence of hyperglycemia and hypoglycemia among patients undergoing major non cardiac surgery

\begin{tabular}{llll}
\hline & $\begin{array}{l}\text { Overall } \\
(N=3150) \\
N(\%)\end{array}$ & $\begin{array}{l}\text { Diabetes No }(N=2384) \\
\mathrm{N}(\%)\end{array}$ & $\begin{array}{l}\text { Diabetes Yes } \\
(\mathrm{N}=766) \\
\mathrm{N}(\%)\end{array}$ \\
\hline $\begin{array}{l}\text { Normoglycemia }(<8.3 \mathrm{mmol} / \mathrm{L}) \\
\text { Hyperglycemia }\end{array}$ & $1619(51)$ & $1360(57)$ & $259(34)$ \\
$\quad$ Mild $(8.3-11.0 \mathrm{mmol} / \mathrm{L})$ & $1042(33)$ & $766(32)$ & $276(36)$ \\
$\quad \begin{array}{l}\text { Moderate }(11.1-16.6 \mathrm{mmol} / \mathrm{L}) \\
\text { Severe }(\geq 16.7 \mathrm{mmol} / \mathrm{L})\end{array}$ & $442(14)$ & $244(10)$ & $198(26)$ \\
Hypoglycemia & $47.0)$ & $14(1.0)$ & $33(4.0)$ \\
$\quad \begin{array}{l}\text { Moderate }(\leq 3.3 \mathrm{mmol} / \mathrm{L}) \\
\text { Severe }(\leq 2.2 \mathrm{mmo} / \mathrm{L})\end{array}$ & $33(1.0)$ & $25(1.0)$ & $8(1.0)$ \\
\hline
\end{tabular}

Hosmer and Lemeshow Test resulted in a chi-square of 3.3, 8 degrees of freedom, and a p-value of 0.92 .

When studying the subset of patients without diabetes, mild hyperglycemia, moderate hyperglycemia, severe hyperglycemia, glucose standard deviation, and GLI did not demonstrate a significant independent relationship. The model's c-statistic was 0.71 [95\% CI 0.69-0.74] and the omnibus test of model coefficients resulted in a chi-square of 195.9, 27 degrees of freedom, and a $p$-value $<0.001$. The Hosmer and Lemeshow Test resulted in a chi-square of 3.0, 8 degrees of freedom, and a p-value of 0.93 .

Classification of hyperglycemia defined as a glucose value $\geq 10 \mathrm{mmol} / \mathrm{L}$ did not demonstrate a statistically significant risk adjusted increase in postoperative infectious complications (AOR 1.06 [95\% CI 0.80-1.40]). Our sensitivity analysis on the use of $\mathrm{RBC}$ intraoperatively demonstrated similar measures of effect sizes for the hyperglycemia groupings (data not shown) and in addition a statistically significant measure of effect size for the number of RBC units administered [[AOR 1.04 (95\% CI 1.00-1.07)].

\section{Discussion}

Our data demonstrate that among a broad range of patients undergoing major non-cardiac surgery, intraoperative glucose levels above $8.3 \mathrm{mmol} / \mathrm{L}$ are associated with a significantly increased risk of postoperative infections. This effect is independent of underlying patient comorbidities, surgical procedure complexity, and surgical duration. A dose-response curve was observed, with mild hyperglycemia resulting in an AOR of 1.30 [95\% CI of 1.01-1.68] and moderate hyperglycemia resulting in an AOR of 1.57 [95\% CI of 1.08-2.28]. Although the data were underpowered to detect a statistically significant increase among patients with severe hyperglycemia, an AOR of 1.70 [95\% CI of 0.67-4.35] was observed. This analysis of 3150 patients is the largest published dataset of intraoperative glucose management and serves to inform future prospective interventional studies.

There are very limited prospective data evaluating the impact of intraoperative hyperglycemia and postoperative outcomes in the non-cardiac surgery population [1]. A recent randomized controlled trial limited to 236 patients undergoing major vascular surgery did find a decreased risk of cardiac adverse events in patients targeted to a glucose level below $8.3 \mathrm{mmol} / \mathrm{L}$, but the patient population and outcome of interest were limited [16]. The primary outcome was a composite outcome of all-cause mortality and two specific cardiac events; myocardial infarction and acute congestive heart failure. Infectious complications were not evaluated. Next, secondary interim analyses of 381 patients enrolled in the Dexamethasone, Light Anesthesia and Tight Glucose 
Table 2 Patient characteristics among studied population

\begin{tabular}{|c|c|c|c|c|}
\hline Co-morbidities & $\begin{array}{l}\text { Normoglycemia } \\
\text { (Glucose }<8.3 \mathrm{mmol} / \mathrm{L}) \\
(\mathrm{N}=1619) \\
\mathrm{N}(\%)\end{array}$ & $\begin{array}{l}\text { Mild hyperglycemia } \\
\text { (Glucose } 8.3-11.0 \mathrm{mmol} / \mathrm{L}) \\
(\mathrm{N}=1042) \\
\mathrm{N}(\%)\end{array}$ & $\begin{array}{l}\text { Moderate hyperglycemia } \\
\text { (Glucose } 11.1-16.6 \mathrm{mmol} / \mathrm{L}) \\
(\mathrm{N}=442) \\
\mathrm{N}(\%)\end{array}$ & $\begin{array}{l}\text { Severe hyperglycemia } \\
\text { (Glucose } \geq 16.7 \mathrm{mmol} / \mathrm{L}) \\
(N=47) \\
\mathrm{N}(\%)\end{array}$ \\
\hline$\overline{\mathrm{Age}^{\mathrm{a}}}$ & $62 \pm 15$ & $63 \pm 13$ & $61 \pm 14$ & $58 \pm 15$ \\
\hline Body mass index $\left(\mathrm{kg} / \mathrm{m}^{2}\right)^{\mathrm{a}}$ & $28 \pm 8$ & $29 \pm 8$ & $30 \pm 8$ & $31 \pm 9$ \\
\hline Male sex & $935(58)$ & $588(56)$ & $229(52)$ & $23(49)$ \\
\hline Emergency Operation & $136(8.4)$ & $81(7.8)$ & $43(9.7)$ & $8(17)$ \\
\hline Dyspnea (any) & $174(11)$ & $115(11)$ & $58(13)$ & $7(15)$ \\
\hline Active Congestive Heart Failure & $16(1.0)$ & $9(0.9)$ & $5(1.1)$ & $4(8.5)$ \\
\hline 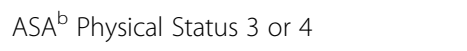 & $1168(72)$ & $767(74)$ & $332(75)$ & $40(85)$ \\
\hline $\begin{array}{l}\text { Functional Status } \\
\text { (Partially or Totally Dependent) }\end{array}$ & $53(3.3)$ & $24(2.3)$ & $12(2.7)$ & $2(4.3)$ \\
\hline Ascites & $19(1.2)$ & $7(0.7)$ & $3(0.7)$ & $1(2.1)$ \\
\hline \multicolumn{5}{|l|}{ Diabetes } \\
\hline Oral Hypoglycemic Treated & $153(9.5)$ & $177(17)$ & $112(25)$ & $12(26)$ \\
\hline Insulin Treated & $105(6.5)$ & $99(9.5)$ & $86(20)$ & $21(45)$ \\
\hline $\mathrm{COPD}^{\mathrm{C}}$ & $152(9.4)$ & $89(8.5)$ & $25(5.7)$ & $3(6.4)$ \\
\hline Hypertension & $956(59)$ & $613(59)$ & $278(63)$ & $31(66)$ \\
\hline Cardiac disease & $365(23)$ & $208(20)$ & $86(20)$ & $13(28)$ \\
\hline Cerebrovascular disease & $210(13)$ & $73(7.0)$ & $47(11)$ & $3(6.4)$ \\
\hline Renal Failure or Dialysis & $53(3.3)$ & $10(1.0)$ & $6(1.4)$ & $2(4.3)$ \\
\hline $\begin{array}{l}\text { Operative duration } \geq 75 \text { th percentile for } \\
\text { case-specific national norms }\end{array}$ & $566(35)$ & $470(45)$ & $222(50)$ & $27(59)$ \\
\hline
\end{tabular}

${ }^{a}$ Continuous parametric data presented as mean \pm standard deviation

${ }^{\mathrm{b}} \mathrm{ASA}=$ American Society of Anesthesiologists

${ }^{c} \mathrm{COPD}=$ Chronic Obstructive Pulmonary Disease

Control (DeLiT) trial did not demonstrate a relationship between intensive insulin therapy and a composite morbidity and mortality endpoint [17].

Even observational trials struggle to offer insight into associations between intraoperative glucose values and postoperative outcomes. Of the many observational studies evaluating glucose control and postoperative outcomes, few have been in the non-cardiac literature, $[10,12-15,30]$ and only two have incorporated intraoperative glucose measurements into the analysis [11, 35]. Eshuis et al. reviewed the glycemic control of 330 patients undergoing elective pancreatoduodenectomy [11]. They did not detect any relationship between intraoperative hyperglycemia and a composite morbidity outcome, but were likely underpowered to detect a difference with only 330 patients. Yoo et al. retrospectively reviewed 304 patients undergoing liver transplantation and demonstrated that glucose

Table 3 Primary outcome details

\begin{tabular}{|c|c|c|c|c|}
\hline Infection type & $\begin{array}{l}\text { Normoglycemia } \\
\text { (Glucose }<8.3 \mathrm{mmol} / \mathrm{L}) \\
(\mathrm{N}=1619) \\
\mathrm{N}(\%)\end{array}$ & $\begin{array}{l}\text { Mild hyperglycemia } \\
(\mathrm{Glucose} 8.3-11.0 \mathrm{mmol} / \mathrm{L}) \\
(\mathrm{N}=1042) \\
\mathrm{N}(\%) \\
\end{array}$ & $\begin{array}{l}\text { Moderate hyperglycemia } \\
\text { (Glucose } 11.1-16.6 \mathrm{mmol} / \mathrm{L}) \\
(\mathrm{N}=442) \\
\mathrm{N}(\%)\end{array}$ & $\begin{array}{l}\text { Severe hyperglycemia } \\
(\mathrm{Glucose} \geq 16.7 \mathrm{mmol} / \mathrm{L}) \\
(\mathrm{N}=47) \\
\mathrm{N}(\%) \\
\end{array}$ \\
\hline$\overline{\text { Superficial SSI }}{ }^{a}$ & $63(3.9)$ & $85(8.2)$ & $29(6.6)$ & $6(13)$ \\
\hline Deep Incisional SSI ${ }^{a}$ & $14(0.9)$ & $15(1.4)$ & $3(0.7)$ & $0(0)$ \\
\hline Organ space SSI ${ }^{a}$ & $30(1.9)$ & $32(3.1)$ & $20(4.5)$ & $0(0)$ \\
\hline Wound disruption & $10(0.6)$ & $9(0.9)$ & $6(1.4)$ & $2(4.3)$ \\
\hline Pneumonia & $36(2.2)$ & $29(2.8)$ & $17(3.8)$ & $0(0)$ \\
\hline Urinary Tract Infection & $69(4.3)$ & $48(4.6)$ & $23(5.2)$ & $3(6.4)$ \\
\hline Sepsis & $45(2.8)$ & $45(4.3)$ & $21(4.8)$ & $0(0)$ \\
\hline
\end{tabular}

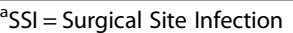




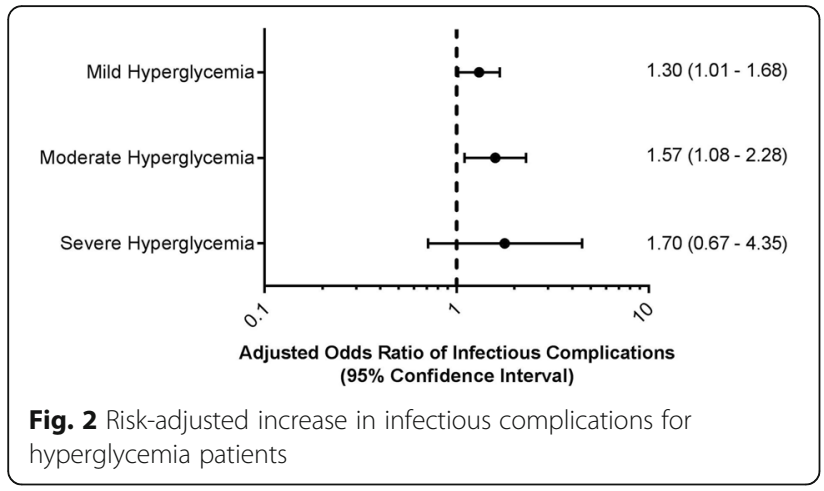

variability increased a patient's risk for postoperative acute kidney injury but not hyperglycemia alone. Our study did include glucose variability in the multivariate modeling but that was not determined to be an independent predictor of postoperative infectious complications [35].

Our data demonstrate that the risk-adjusted association between hyperglycemia and postoperative infections is present with increasing severity of hyperglycemia resulting in an increased risk of infectious complications after adjusting for surgical complexity and patient pre-existing comorbidities. From a pathophysiologic viewpoint, hyperglycemia is associated with increased inflammation, impaired chemotaxis and phagocytosis, and vulnerability to infections $[1,6]$. The cardiac surgery literature has extensive observational and some prospective randomized trial data to support the relationship between improved glycemic control and decreased surgical site infections $[1,6]$. Though our data demonstrates an association between intraoperative hyperglycemia and postoperative infections in patients undergoing non-cardiac surgeries, the causal relationship still remains unclear.

There is a lack of published guidelines regarding intraoperative glucose management in the diabetic or non-diabetic patient undergoing non-cardiac surgeries. The results of this study highlights the significance of intraoperative glucose levels and in addition questions the practice pattern of casually dismissing an intraoperative glucose measurement of $10 \mathrm{mmol} / \mathrm{L}$ as some medical societies have recommended [31,32]. We have demonstrated that when a binary threshold for hyperglycemia defined as a glucose $\geq 10 \mathrm{mmol} / \mathrm{L}$ is used, there is no significant effect size measures associated with postoperative infections. However, in contrast, when three separate ranges of intraoperative hyperglycemia levels are used, a dose-response curve is seen. These data may suggest that more patients undergoing major non-cardiac surgery warrant intraoperative glucose measurement. At the very least, intraoperative hyperglycemia warrants a discussion with the surgical team to inform them of the patient's elevated risk of postoperative infections. In this dataset, more than half of patients undergoing major non-cardiac surgery did not have an intraoperative glucose measurement (Fig. 1). In general, these patients were healthier and less likely to have a preoperative diagnosis of diabetes (data not shown). It should be noted that the observed relationship between hyperglycemia and increased infectious complications was observed in the primary analysis and our sensitivity analysis incorporating the number of RBC units administered intraoperatively. Glucose measurement and management must broaden its scope from the diabetic patient undergoing non-cardiac surgery to all patients including non-DM patients undergoing major surgery.

There are several limitations to this study. As an observational study, an association between intraoperative hyperglycemia and postoperative infection was demonstrated, but causal relationship could not be established. Despite adjusting for a variety of comorbidities and surgical factors, residual confounding may be present. Several factors that impact infectious complications, such as antibiotic choice, normothermia, and pre-existing immunity deficient states (HIV/AIDS and disseminated cancer) were not incorporated into the analysis. In our database, only 4 patients were diagnosed with HIV/AIDS. This sample size is very small and will not affect the measures of effect sizes on mild and moderate hyperglycemia demonstrated in our primary analysis. We also have 155 patients (4.9\%) with a preoperative diagnosis of disseminated cancer. Hyperglycemia, like a suppressed immune system, are only modifiers of susceptibility to infections. Therefore, we did not exclude those patients from the database. Next, the analysis does not address the effect of hyperglycemia treatment. Although many patients did receive intraoperative insulin treatment and these data are reported, the logistic regression did not include insulin treatment as a covariate because insulin treatment is a marker of hyperglycemia itself. Larger observational studies are needed to compare patients with similar hyperglycemia profiles with and without insulin treatment to ascertain an insulin treatment effect. Until then the real risks of hyperglycemia must be weighed against the independent relationship that we observed between intraoperative hyperglycemia and postoperative infection. The point estimates for hyperglycemia may demonstrate a dose response curve, however the wide confidence interval for severe hyperglycemia may indicate it's not. In addition, the NSQIP definitions of SIRS, sepsis, and septic shock have been enhanced recently. Unfortunately, we do not have the specific data elements available (positive blood culture, clinical documentation or purulence, or suspected pre-operative clinical condition or infection or bowel infarction) that are included in the new definition to adequately perform a sensitivity analysis. At our institution, there are no differences in rates of prophylactic antibiotic administration. These data were collected using internal 
quality assurance metrics and are unable to be linked to this database to allow a propensity score matched analysis to address any potential confounding between prophylactic antibiotic administration and infectious outcomes. It is feasible, that our sample size in the study cohort would be reduced and the dose response curve in intraoperative hyperglycemia and postoperative infectious complications may differ. Although these data add to the non-cardiac literature, the patient population is limited to major general, vascular, and urologic surgery; other common procedures warrant further investigation. The single-center nature of the dataset also limits the generalizability of the conclusions. The data, due to low sample size, were also underpowered to detect a difference among patients experiencing severe hyperglycemia and a sensitivity analysis focused on diabetic patients only was not feasible. Therefore, future clinical trials are needed to focus on diabetic patients. We also acknowledge that the overall composite infection rate is high $(15 \%)$ in relation to previously published research. However, the individual infection outcomes (Table 3) have an overall incidence ranging from $0.9-5.8 \%$. NSQIP methodology ensures high quality surgical clinical reviewer extraction for all data elements with less than $2 \%$ disagreement in inter-rater reliability audit checks.

\section{Conclusions}

Despite these limitations, these data are impactful and novel. More than 3000 patients undergoing a variety of major non-cardiac surgeries were studied, representing the largest observational dataset regarding intraoperative hyperglycemia in non-cardiac surgery to date. The data clearly demonstrate a dose-dependent relationship between intraoperative hyperglycemia and postoperative infectious complications after risk adjustment for major comorbidities. Intraoperative hyperglycemia is an independent predictor of infectious complications among both diabetic and non-diabetic patients and must become a focus among practicing anesthesiologists. These data demand further exploration beyond infectious complication via larger, multicenter observational datasets and prospective, randomized control trials to establish whether treatment of hyperglycemia may alter outcomes. Non diabetic patients and impact of glucose variability is worth exploring including the value of commercially available continuous glucose monitoring.

\section{Additional files}

Additional file 1: Appendix 1. American College of Surgeons -

National Surgery Quality Improvement Program Data Element Definitions. (DOC $44 \mathrm{~kb})$
Additional file 2: Appendix 2. American College of Surgeons National Surgery Quality Improvement Program Data Outcome Definitions. (DOC $58 \mathrm{~kb}$ )

Additional file 3: Appendix 3. Frequency and Infectious Complication Data by Procedure Description. (DOCX $18 \mathrm{~kb}$ )

Additional file 4: Appendix 4. Intraoperative Maximum Glucose Distribution for Patients With and Without Postoperative Infectious Complications. Box and whisker plots for maximum intraoperative blood glucose value (mmol/L) by overall complication infectious complication as well as individual infectious complications. Abbreviations: SSI = Surgical Site Infection, UTI = Urinary Tract Infection. (TIF $381 \mathrm{~kb}$ )

\section{Abbreviations}

AOR: Adjusted Odds Ratio; ASA: American Society of Anesthesiologists; Cl: Confidence Interval; COPD: Chronic Obstructive Pulmonary Disease; CPT: Common Procedural Terminology; EHR: Electronic Health Record; GLI: Glycemic Lability Index; IIT: Intensive Insulin Therapy; NSQIP: National Surgical Quality Improvement Program; SSI: Surgical Site Infection

\section{Funding}

This work was supported by funding attributed to the Department of Anesthesiology at the University of Michigan Medical School. The project described was supported in part by the National Center for Research Resources, Grant UL1RR024986, which is now at the National Center for Advancing Translational Sciences, Grant 2UL1TR000433. The content is solely the responsibility of the authors and does not necessarily represent the official views of the National Institutes of Health.

\section{Availability of data and materials}

NSQIP is a national dataset owned by the American College of Surgeons. Data is only available to the members via contacting the American College of Surgeons. Electronic health records were abstracted locally at our Institution by an honest broker and is not publically available.

\section{Authors' contributions}

AMS: Study conception and design, acquisition of data, analysis and interpretation of data, drafting of manuscript, and critical revision of manuscript. SK: Study conception and design, acquisition of data, analysis and interpretation of data, drafting of manuscript, and critical revision of manuscript. DTW: Drafting of manuscript and critical revision of manuscript. SK: Critical revision of manuscript. DAC: Study conception and design and critical revision of manuscript. All authors read and approved the final manuscript.

\section{Ethics approval and consent to participate}

Institutional review board approval (University of Michigan, Ann Arbor, Michigan, HUM 00077498) was obtained for this retrospective observational study at a single academic medical center. As there were no care interventions involved and protected health information were removed after the dataset was created, patient consent was waived as part of the approval.

\section{Consent for publication}

Not applicable.

\section{Competing interests}

The authors declare that they have no competing interests.

\section{Publisher's Note}

Springer Nature remains neutral with regard to jurisdictional claims in published maps and institutional affiliations.

\section{Author details}

${ }^{1}$ Department of Anesthesiology, Michigan Medicine, 1500 E. Medical Center Dr., SPC 5048, Ann Arbor, Ml 48109, USA. ${ }^{2}$ Department of Surgery, Michigan Medicine, 1500 E. Medical Center Dr., SPC 5825, Ann Arbor, Ml 48109, USA. 
Received: 7 June 2017 Accepted: 20 June 2018

Published online: 19 July 2018

\section{References}

1. Lipshutz AK, Gropper MA. Perioperative glycemic control: an evidencebased review. Anesthesiology. 2009;110(2):408-21.

2. Wiener RS, Wiener DC, Larson RJ. Benefits and risks of tight glucose control in critically ill adults: a meta-analysis. Jama. 2008;300(8):933-44.

3. Ouattara A, Lecomte P, Le Manach Y, Landi M, Jacqueminet S, Platonov I, Bonnet N, Riou B, Coriat P. Poor intraoperative blood glucose control is associated with a worsened hospital outcome after cardiac surgery in diabetic patients. Anesthesiology. 2005;103(4):687-94.

4. Gandhi GY, Nuttall GA, Abel MD, Mullany CJ, Schaff HV, Williams BA, Schrader LM, Rizza RA, McMahon MM. Intraoperative hyperglycemia and perioperative outcomes in cardiac surgery patients. Mayo Clin Proc. 2005;80(7):862-6.

5. Russo N. Perioperative glycemic control. Anesthesiol Clin. 2012;30(3):445-66.

6. Inzucchi SE. Clinical practice. Management of hyperglycemia in the hospital setting. N Engl J Med. 2006:355(18):1903-11.

7. Finfer $S$, Chittock DR, Su SY, Blair D, Foster D, Dhingra V, Bellomo R, Cook D, Dodek $\mathrm{P}$, Henderson WR, et al. Intensive versus conventional glucose control in critically ill patients. N Engl J Med. 2009;360(13):1283-97.

8. Marik PE, Varon J. Intensive insulin therapy in the ICU: is it now time to jump off the bandwagon? Resuscitation. 2007;74(1):191-3.

9. Van den Berghe G, Wilmer A, Hermans G, Meersseman W, Wouters PJ, Milants I, Van Wijngaerden E, Bobbaers H, Bouillon R. Intensive insulin therapy in the medical ICU. N Engl J Med. 2006;354(5):449-61.

10. DiNardo M, Donihi AC, Forte P, Gieraltowski L, Korytkowski M. Standardized glycemic management and perioperative glycemic outcomes in patients with diabetes mellitus who undergo same-day surgery. Endocr Pract. 2011;17(3):404-11.

11. Eshuis WJ, Hermanides J, van Dalen JW, van Samkar G, Busch OR, van Gulik TM, DeVries JH, Hoekstra JB, Gouma DJ. Early postoperative hyperglycemia is associated with postoperative complications after pancreatoduodenectomy. Ann Surg. 2011;253(4):739-44.

12. Jackson RS, Amdur RL, White JC, Macsata RA. Hyperglycemia is associated with increased risk of morbidity and mortality after colectomy for cancer. J Am Coll Surg. 2012;214(1):68-80.

13. King JT Jr, Goulet JL, Perkal MF, Rosenthal RA. Glycemic control and infections in patients with diabetes undergoing noncardiac surgery. Ann Surg. 2011;253(1):158-65.

14. Ramos M, Khalpey Z, Lipsitz S, Steinberg J, Panizales MT, Zinner M, Rogers SO. Relationship of perioperative hyperglycemia and postoperative infections in patients who undergo general and vascular surgery. Ann Surg. 2008;248(4):585-91.

15. Sehgal R, Berg A, Figueroa R, Poritz LS, McKenna KJ, Stewart DB, Koltun WA. Risk factors for surgical site infections after colorectal resection in diabetic patients. J Am Coll Surg. 2011;212(1):29-34.

16. Subramaniam B, Panzica PJ, Novack V, Mahmood F, Matyal R, Mitchell JD, Sundar E, Bose R, Pomposelli F, Kersten JR, et al. Continuous perioperative insulin infusion decreases major cardiovascular events in patients undergoing vascular surgery: a prospective, randomized trial. Anesthesiology. 2009;110(5):970-7.

17. Abdelmalak BB, Bonilla A, Mascha EJ, Maheshwari A, Tang WH, You J, Ramachandran M, Kirkova Y, Clair D, Walsh RM, et al. Dexamethasone, light anaesthesia, and tight glucose control (DeLiT) randomized controlled trial. Br J Anaesth. 2013;111(2):209-21.

18. Abdelmalak B, Maheshwari A, Kovaci B, Mascha EJ, Cywinski JB, Kurz A, Kashyap VS, Sessler DI. Validation of the DeLiT trial intravenous insulin infusion algorithm for intraoperative glucose control in noncardiac surgery: a randomized controlled trial. Can J Anaesth. 2011;58(7):606-16.

19. Ehrenfeld JM, Wanderer JP, Terekhov M, Rothman BS, Sandberg WS. A perioperative systems design to improve intraoperative glucose monitoring is associated with a reduction in surgical site infections in a diabetic patient population. Anesthesiology. 2017;126(3):431-40.

20. Khuri SF, Daley J, Henderson W, Barbour G, Lowry P, Irvin G, Gibbs J, Grover F, Hammermeister K, Stremple JF, et al. The National Veterans Administration Surgical Risk Study: risk adjustment for the comparative assessment of the quality of surgical care. J Am Coll Surg. 1995;180(5):519-31.
21. Khuri SF, Henderson WG, Daley J, Jonasson O, Jones RS, Campbell DA Jr, Fink AS, Mentzer RM Jr, Steeger JE. Principal site investigators of the patient safety in surgery S: the patient safety in surgery study: background, study design, and patient populations. J Am Coll Surg. 2007;204(6):1089-102.

22. Meynaar IA, van Spreuwel M, Tangkau PL, Dawson L, Sleeswijk Visser S, Rijks $\mathrm{L}$, Vlieland TV. Accuracy of AccuChek glucose measurement in intensive care patients. Crit Care Med. 2009;37(10):2691-6.

23. Boyd AD, Hosner C, Hunscher DA, Athey BD, Clauw DJ, Green LA. An 'Honest Broker' mechanism to maintain privacy for patient care and academic medical research. Int J Med Inform. 2007;76(5-6):407-11.

24. Ali NA, O'Brien JM Jr, Dungan K, Phillips G, Marsh CB, Lemeshow S, Connors AF Jr, Preiser JC. Glucose variability and mortality in patients with sepsis. Crit Care Med. 2008;36(8):2316-21.

25. Analysis of the Future: The Dephi Method. 1967. https://www.rand.org/ pubs/papers/P3558.html. Accessed 12 June 2018.

26. Faraway JJ. Linear models with R. Boca Raton: Chapman and Hall; 2004.

27. Dimick JB, Osborne NH, Hall BL, Ko CY, Birkmeyer JD. Risk adjustment for comparing hospital quality with surgery: how many variables are needed? J Am Coll Surg. 2010;210(4):503-8.

28. Raval MV, Cohen ME, Ingraham AM, Dimick JB, Osborne NH, Hamilton BH, Ko CY, Hall BL. Improving American College of Surgeons National Surgical Quality Improvement Program risk adjustment: incorporation of a novel procedure risk score. J Am Coll Surg. 2010;211(6):715-23.

29. Houle $\Pi$. Importance of effect sizes for the accumulation of knowledge. Anesthesiology. 2007;106(3):415-7.

30. Hanley JA, McNeil BJ. The meaning and use of the area under a receiver operating characteristic (ROC) curve. Radiology. 1982;143(1):29-36.

31. Joshi GP, Chung F, Vann MA, Ahmad S, Gan TJ, Goulson DT, Merrill DG, Twersky R. Society for Ambulatory a: Society for Ambulatory Anesthesia consensus statement on perioperative blood glucose management in diabetic patients undergoing ambulatory surgery. Anesth Analg. 2010;111(6):1378-87.

32. Lazar HL, McDonnell M, Chipkin SR, Furnary AP, Engelman RM, Sadhu AR, Bridges CR, Haan CK, Svedjeholm R, Taegtmeyer H, et al. The Society of Thoracic Surgeons practice guideline series: blood glucose management during adult cardiac surgery. Ann Thorac Surg. 2009;87(2):663-9.

33. Glance LG, Dick AW, Mukamel DB, Fleming FJ, Zollo RA, Wissler R, Salloum $\mathrm{R}$, Meredith UW, Osler TM. Association between intraoperative blood transfusion and mortality and morbidity in patients undergoing noncardiac surgery. Anesthesiology. 2011;114(2):283-92.

34. Chu Y, Shanks A, Kheterpal S. A1713: hyperglycemia in diabetics undergoing non-cardiac surgery and postoperative outcomes. In: American Society of Anesthesiologists Annual Meeting: 2011; 2011.

35. Yoo S, Lee HJ, Lee H, Ryu HG. Association between perioperative hyperglycemia or glucose variability and postoperative acute kidney injury after liver transplantation: a retrospective observational study. Anesth Analg. 2017;124(1):35-41.

\section{Ready to submit your research? Choose BMC and benefit from:}

- fast, convenient online submission

- thorough peer review by experienced researchers in your field

- rapid publication on acceptance

- support for research data, including large and complex data types

- gold Open Access which fosters wider collaboration and increased citations

- maximum visibility for your research: over $100 \mathrm{M}$ website views per year

At BMC, research is always in progress.

Learn more biomedcentral.com/submissions 